\title{
A Pilot Study into Mapping Atypical Supply Networks
}

\author{
Mark Edwards ${ }^{1}$, Pauline J. Ross ${ }^{2, *}$, Lee E. J. Styger ${ }^{1}$ \\ ${ }^{1}$ Sydney Business School, University of Wollongong, Australia \\ ${ }^{2}$ Faculty of Health, Engineering and Sciences, University of Southern Queensland, Australia
}

Copyright $\mathrm{O} 2018$ by authors, all rights reserved. Authors agree that this article remains permanently open access under the terms of the Creative Commons Attribution License 4.0 International License

\begin{abstract}
A system can only be improved if it is measured. In order to adequately measure a system, that system needs to be mapped and all key inter-nodal linkages, constraints and pathways recorded. Commercial supply chains demonstrate similar characteristics to other systems. Much has been written about mapping supply systems, where typically, the product or service is tracked from the originating source such as a raw materials supplier to the end customer of the product such as the consumer. There is however, another classification of supply system, where the payment for the product or service is not undertaken by the end consumer. This supply system is more often associated with not-for-profit (NFP) and non-government organisation (NGO) activities and little has been written concerning the mapping of these atypical supply systems. This is unfortunate, as it is often these types of networks that are most assumed to be inefficient and lacking appropriate quality measures. This paper discusses the characteristics of atypical supply networks and also describes a method of mapping them by using an auditing approach based on tracking funding through the system and not the flow of products or services within it. We argue that this approach is robust, because it enables the actual flow patterns within the network to be identified and not confused with, often, conflicting demands placed on atypical supply networks by the multiple stakeholders often associated with them.
\end{abstract}

Keywords Supply Chain Mapping, Systems Mapping, Atypical Supply Chain, Aid and Development, University Research, Measurement

\section{Introduction}

The principles of supply chain management have long been established in both academic literature and the business at large. Typically a supply chain is considered to consist of a series of interlinked nodes that, via logistics activities, add value to a raw material of some kind resulting in a final, finished product for the end customer. In the context of this work, the end customer (principal) is defined as the person or entity who puts 'new money' or original funding into the system.

In traditional supply chain systems mapping, the transfer of value from node to node is often easy to establish from, either an end customer point of view by following a straight forward investigation process of "what happens before" (i.e. a retrospective investigation), or from a raw material side following a process of "what happens next" (i.e. a futuristic investigation). In either instance, the line of inquiry can be mapped as either a flow diagram and/or a transfer and motion type diagram. Additionally, in both instances of mapping, the values and associated linkages can be established and a model or simulation of the supply chain system produced [1]. There is extensive literature from both academic and business sources that document and describe the typical mapping of the system [2]. However, the literature contains little information on mapping a system where the payment for the product or service is not undertaken by the end consumer. This supply system is considered atypical and more often associated with not-for-profit (NFP) and non-government organisation (NGO) activities. This paper discusses the mapping of atypical supply networks and undertakes a mapping of case studies to test the robustness of the process.

Commercial supply chain systems that demonstrate a "raw" material and "end" customer nodes are often complex, but reasonably straight forward to map because they often follow established business rules. What is less well understood are those supply chain systems that do not follow the prescribed pattern or flow of goods and services. These atypical supply chain systems often include a situation where the end customer is the entity who injects "new money" into the system but is not always the end recipient (beneficiary) of the good or services. Atypical supply systems are typically associated with activities such as aid and development, NGO works, government activities, and indeed, academic research funding, for example. The "new money" injected into the 
system is often in the form of funding provided as the enabler to a problem solution, for example; government funding of a humanitarian crisis, the provision of social welfare services within local communities, or, the funding through competitive tendering of university research [3-5].

This situation raises an interesting paradox insofar as these atypical supply chain systems are typically associated with high spend activities with uncertain outcomes, often undertaken in a remote environment from the end customer who provides the funding. This remoteness assists with the supply network being misunderstood due to the disconnection between the funder and the supply network; the complex nature of the project; and, most often, the lack of developed mapping processes. As such, these systems are often accused of being inefficient, or worse still, corrupt [6-10].

\section{Objectives}

It has long been established that if a system can be measured, then it can be improved [11-12]. Additionally, the system must be mapped if it is to be measured for improvement to occur. As noted previously, much work has been conducted to establish robust measurement tools for traditional "commercial" type supply chain systems.

A commercial supply chain system is a large system comprising of smaller systems that work within their own boundaries towards a common goal, the end customer.
These systems have interconnected nodes, each of which adds value to the next [13-16]. The mapping and recording of commercial supply chain systems was first demonstrated within the manufacturing industry in the 1950's through Deming's interconnected and continuous improvement process, the Deming's [12] View of a Production System. Deming's model (see Figure 1.) has provided the basis for improvement tools developed over time to enable the measurement of value, quality and sustainability in commercial supply chain systems [17-19]. Post the identification of the system (i.e. the supply chain system map) other tools existed to improve the system and/or redesign the system and manage it, for example, Quality Management Systems such as ISO 9001:2015, LEAN, Six Sigma and SCOR [17, 20-22].

The measurement of a typical supply chain system is undertaken through the identification of a tangible input of materials or service and the mapping of this tangible constant from input to value added output $[1,16]$. The mapping of the supply chain system identifies the value-addition of the inputs in the system; the process of developing the raw materials into a value added product; the output of the product and its relationship to the customers' specification and finally the exchange of money for the product or service. It is important to note that the new money entering into a commercial supply chain system is paid by the recipient of the goods (the end customer) on the provision of the end product (output). Figure 2 illustrates an Industrial Supply Chain System and the Counter Flow of Money within the System.

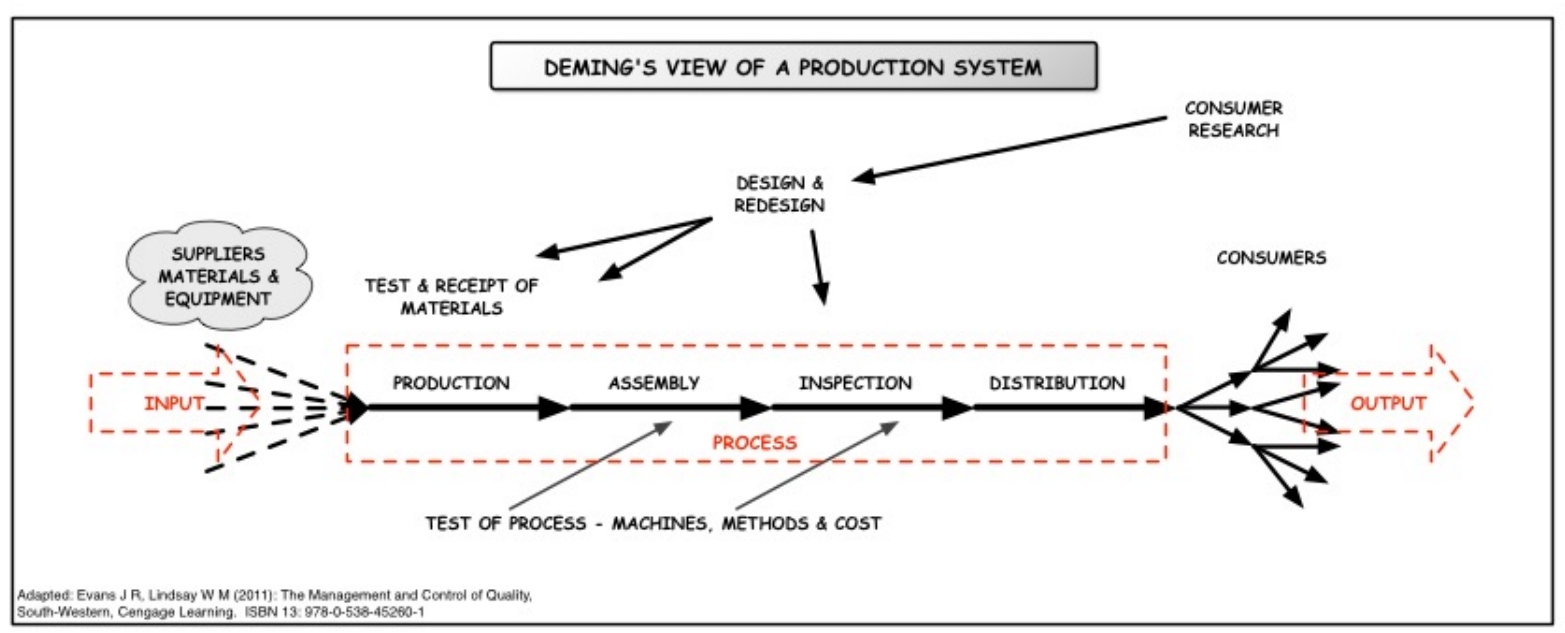

Figure 1. Illustration of Deming View of a Production System. Adapted: Evans and Lindsay 2011 [32] 


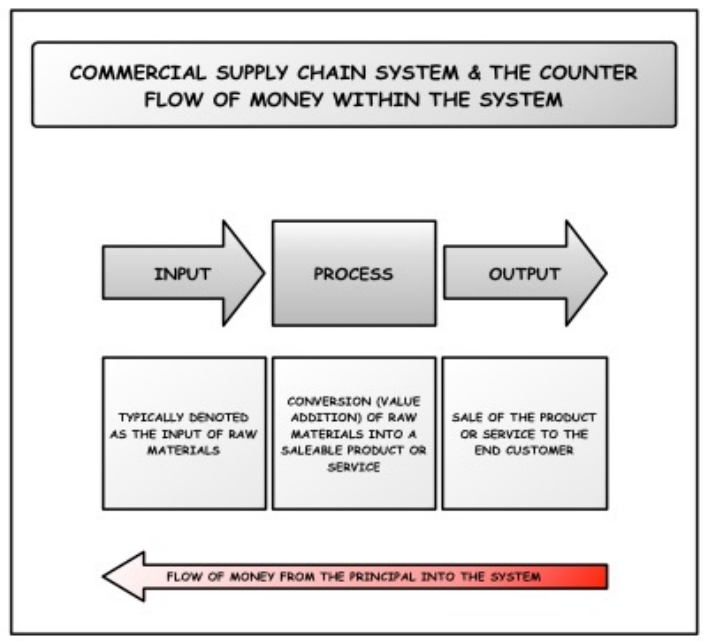

Figure 2. Illustration of an Industrial Supply Chain System and the Counter Flow of Money within the System

Unfortunately, less work has been conducted around the mapping, measuring and improving of atypical supply chain systems that are, by their very nature, more complex and containing more variables due to the plural nature of the products yielded by the system (i.e. the benefit to the customer and the consumer). Where the literature does address the end-to-end mapping of an atypical supply system, it does outline the supply from a limited specific angle, such as, how many human hours were invested; the measurement of tangible product being shipped between countries; or, the outcome of a research grant. Whereas, this is vital, mapping of specific elements of the supply network, often undertaken to respond to stakeholder enquiries, the literature does not provide a discussion on the holistic (end-to-end) measurement of the flow of value within the system [23, 24].

Conceptually, the supply chain systems of both aid and development and university research and development were typically represented as a linear path from the identification of need or opportunity to an output or deliverable from the system. Although a closed loop of supply is perceived to be present in both of the atypical supply systems, critical interactions and players were not identified, because each node represented a destination point within the linear system rather than a value addition to that system (i.e. from a need / raw material input to finalised output).

Figure 3. illustrates the conceptual linear supply chain system of aid and development. The concept of this linear model is that a crisis is identified by the lead agency, who in turn, seek funding from a governing body, when funding is received by the lead agency, second and third tier suppliers are tasked with addressing the crisis (i.e. providing the aid). The measurement of this model typically reports the outcomes of the funding, not the "value for money" attained. The model is reliant on understanding the forward flow of the need.

Along the same lines, Figure 4. illustrates the conceptual linear supply chain system of university research and development. As with the Aid and Development Linear Model described in Figure 3.0, the measurement is typically undertaken from the view of the flow of need (i.e. forward), with reporting typically outlining the outcome of the research funding and not the return on value for research funding dollar or the institution.

The concept of mapping these atypical supply networks was tested against two test sectors (aid and development and university research and development). It was found that post the atypical mapping process, where the funding was tracked into the system; it became apparent that the conceptual models bore little resemblance to the mapped models. This is interesting and suggests that a common axiom of supply thinking exists within a progression type framework and value in the supply chain has typically been measured along the flow of need.

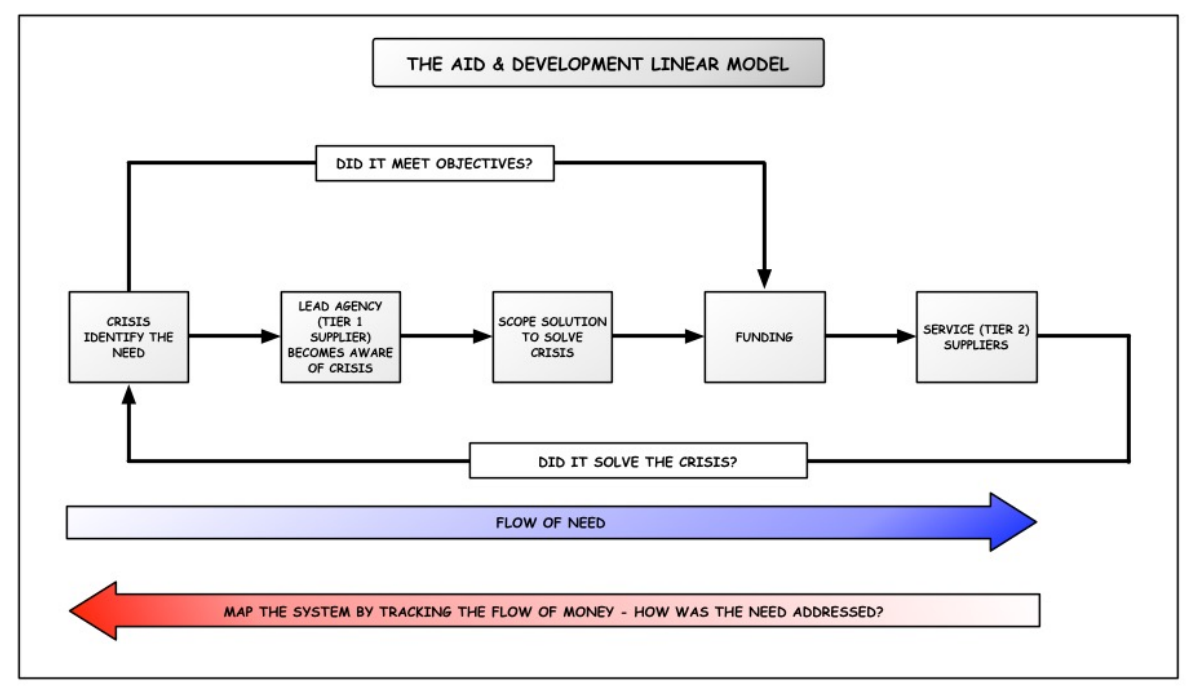

Figure 3. A Conceptual Model of a Linear Aid and Development Supply Chain System 


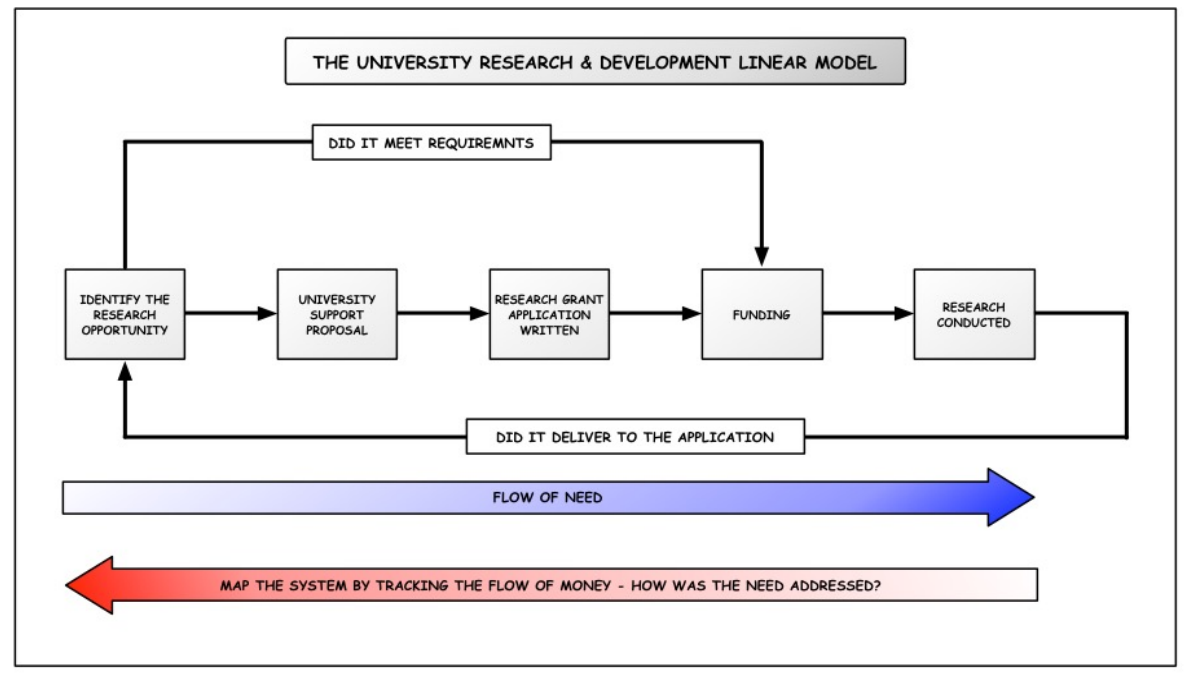

Figure 4. A Conceptual Model of a Linear University Research and Development Supply Chain System

\section{Methods}

Two main issues have been identified concerning the mapping of atypical supply chain systems, these are:

Establishing the Efficacy of Atypical Supply Chain Systems - Establishing if atypical supply chain systems demonstrate similar attributes to commercial supply chain systems and if so, could improvement tools used within commercial supply chain management and improvement be used to manage and improve the atypical supply chain systems.

Finding the Constants to Map an Atypical Supply Chain System - How to overcome the multiple point entry into an atypical supply chain system and plural of beneficiary and customer associated with an atypical supply chain system.

\subsection{Establishing the Efficacy of Atypical Supply Chain Systems}

At face value, there appears to be reluctance in the literature to recognise atypical supply chain systems as supply chain systems at all, let alone, consider the complexities of those systems. Much of this reluctance might be due to main stream researchers following a line of inquiry based on commercial supply chains such as retail [25], automotive [26], aerospace [27] etc., or looking at linear supply chain systems such as medical practice [28], where an entity can be tracked from its entry point into the system, through to its 'value added' exit point from the system. As such, much of this body of work has focused on the product of the system being the constant and not necessarily the trigger of the system [14].

\subsection{Finding the Constants to Map an Atypical Supply Chain System}

The major challenge of this work to date has been establishing a constant within an atypical supply chain system that could be tracked, measured and used to identify key nodes within the system. Most mapping methodologies focus on using the product in, and output of the product in the supply chain system as a constant. As such, within a traditional supply network it is reasonably straight forward to trace the product, even in its raw form, from the point of entry into the system to its point of exit to the end customer, and therefore making it possible to measure it.

This is not, however, often possible within an atypical supply chain system, where the end customer who injects the funding into that system to initiate the "flow" in that system, is not usually the recipient of the end product produced from that system. Put simply, our challenge and indeed argument, has been that a significant element of an atypical supply chain system - the money provider - who is not the recipient, cannot be negated from the mapping process of that system for an easy, or indeed, to enable a "fit of convenience" for more standard mapping processes of commercial supply chain systems.

To add more complexity, the constant that is to be mapped to the end customer, is not readily obvious. The duality of the beneficiaries of the supply network, the principal (funder) and the recipient of the product of service, do not make obvious the identification of a single constant for measurement.

It was thought that the performance of money could be used as the constant in these atypical supply networks. Money can be traced from the input by the funder at the beginning of the system, through to the output that has been created for both the principal (funder) and the recipient of the system. Using money will enable a holistic look at the process as, typically, money is needed to ensure any supply network functions, including aid and development and social welfare provision. Mapping the path of money through the whole system provides a visual 
of how the supply system operates, identifying the constraints on the flow of the system and any opportunities to add value. The success of the mapping of the flow of a tangible element through a system that was not a product of the system, to map constraints and opportunities, was demonstrated in the Healthcare system. This was undertaken by mapping the path of a drug from entry into the system to exit to understand the value created by the processes of patient healthcare [28].

\subsection{The Process of Mapping an Atypical Supply Chain}

The design for this mapping process exploits an open, appreciative inquiry methodology that seeks to understand the process of supply through stakeholders experiences and challenges within the system [29]. To elicit these responses from the principal (i.e. provider of new funding in the system) and consecutive stakeholders in the process, questions were posed regarding:

Establish if the entity considers itself to be the initiating funder of the system in question.

Who the principal passed the funding to next in the system.

What that entity did to add value for the principal.

What that entity did to add value in the product (output of the system) for the recipient.

Who they, the principal, considered to be the recipient of the system the principal has triggered. This latter point provided a cross reference to establish if there was consistency of purpose between nodes ("players") in the atypical supply chain system.

What was the instruction to the next in line (i.e the supplier) and how much was the funding.

For this research, the mapping of an atypical supply chain was designed in a six-step process, however, a number of the steps are to be undertaken in a cyclic manner until the data is exhausted. These steps (listed below) question the participant on the part they play within the system, no matter where they are in the system, using the questions listed above as an appreciative base. Figure 5. illustrates the process adopted to map an atypical supply system including the flow of funding and flow of product within the system.

Step 1 Identify the principal (funder). The funder is defined as the person or entity who released the 'new money' into the system to trigger flow
Step 2 Identify the next player or participant in the system. Who was the funding passed to?

Step 3 From the information gained in Step 2, identify the next player or participant in the system. Step 2 and 3 are to be repeated until the end of the process of funding is reached

Step 4 At the point no further transfer of funding to initiate the supply process to another player. Identify what was produced as the product (output) of the system.

Step 5 Repeat Step 4 until there are no more suppliers to transfer the product to. Identify what was produced as the product (output) of the system.

Step 6 The recipient. Identify what was delivered as the product (output) of the system.

The mapping of this process provides a rich data source of the contact points, stakeholders, processes, flow of information, and most importantly, the flow of return on investment (ROI) in the system.

Work to date suggests that by adopting this approach, a rich data set is developed that enables key nodes and sub-nodes to be established and also the actual and implicit and implied flow within the atypical supply chain system, recipient and end customer ${ }^{1}$. The work to date has also identified the data from the case study mapping identifies what was "actually done" within the supply system, rather than a more nebulous 'should do' that can be the result of a traditional forward mapping approach.

\section{Results}

To establish if this process of mapping an atypical supply network was robust, test cases from two different sectors were undertaken. In both sectors, three separate case studies from aid and development and university research were mapped using the process illustrated in Figure 5. The aid and development cases were sourced from aid projects in Vietman, Kenya and Togo. The university projects were publicly funded research projects from three Australian Universities.

Maps were generated using the data sets derived from the line of inquiry and a "model" of each test case developed from the synthesised data. Figures 6 . and 7. illustrate the model of atypical supply chain system for aid and development and university research respectively. 


\section{THE PROCESS OF MAPPING AN ATYPICAL SUPPLY CHAIN SYSTEM}

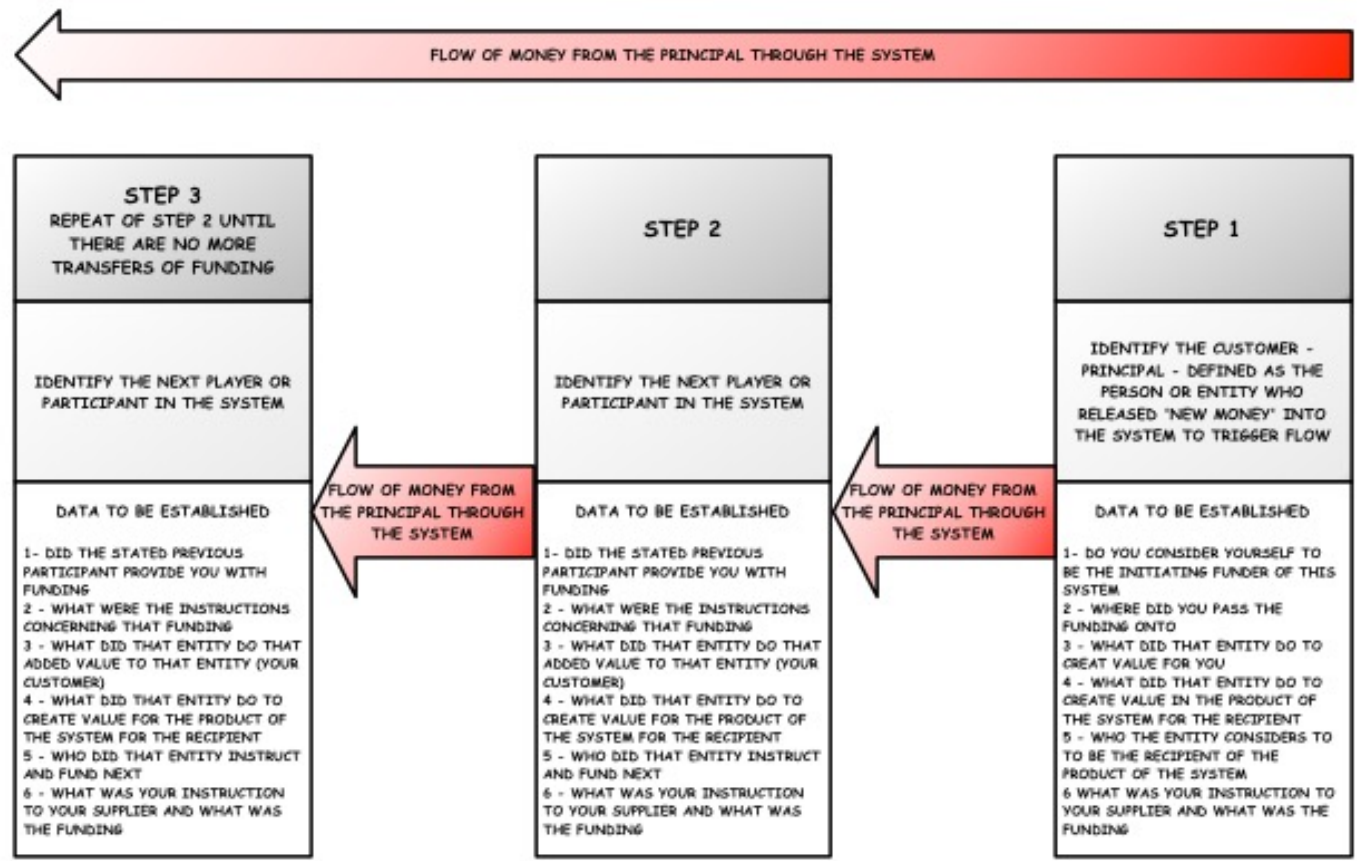

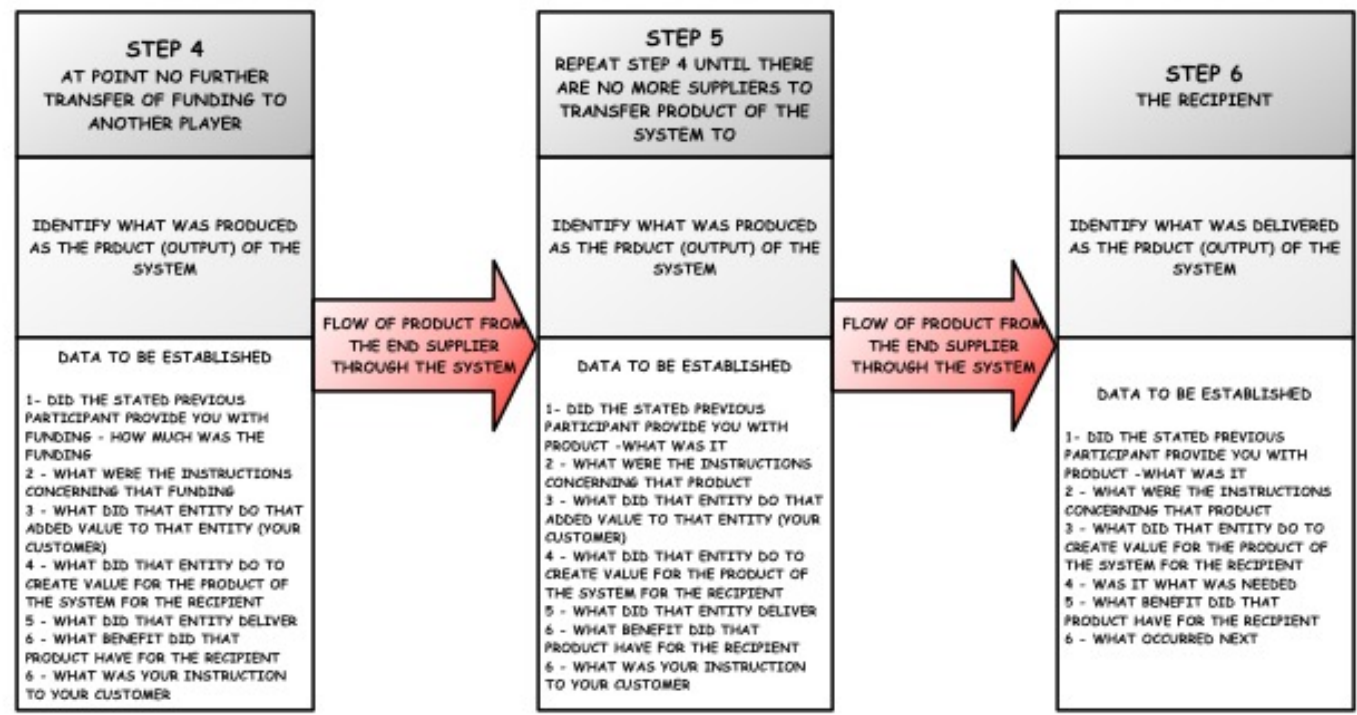

FLOW OF PRODUCT OF THE SYSTEM FROM THE END SUPPLIER TO THE RECIPIENT 


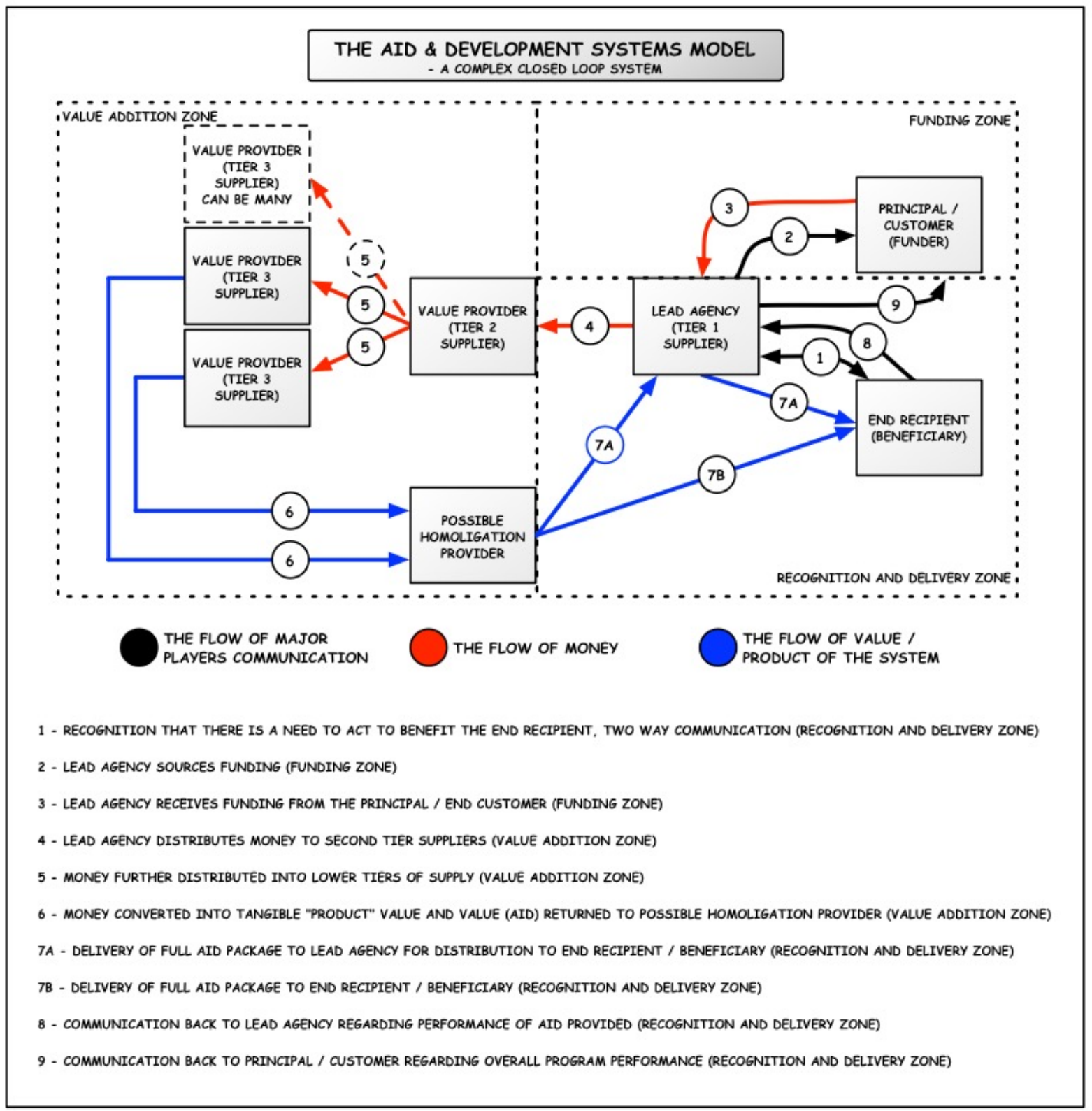

Figure 6. Model of an Aid and Development Atypical Supply Chain Developed from the Mapping Process 


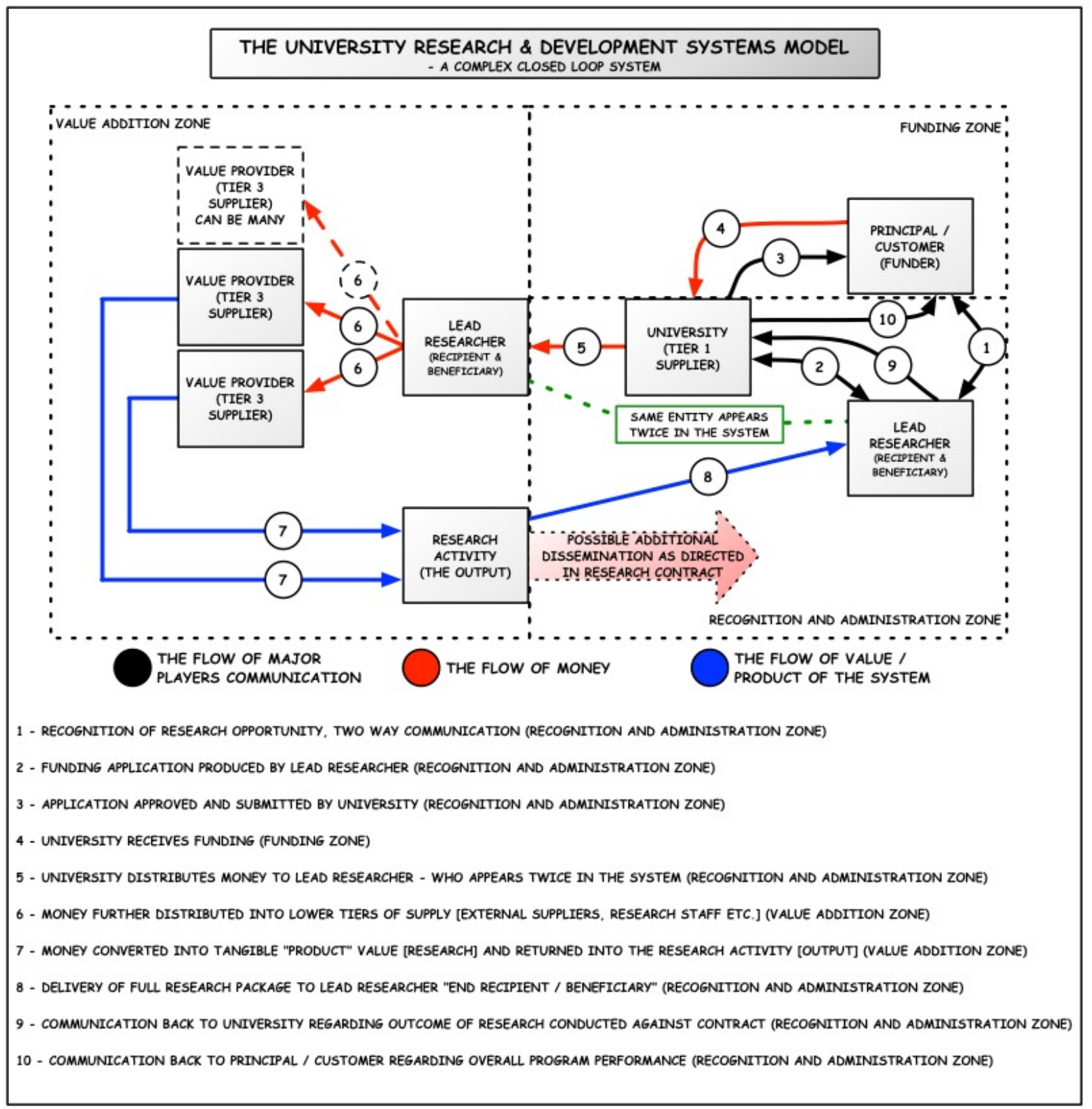

Figure 7. Model of a University Research Atypical Supply Chain Developed from the Mapping Process

\section{Discussion}

The work to date has raised three interesting implications, these are:

The conceptual construct of an atypical supply chain system is linear and does not represent the inherent closed loop dependency of principal and recipient as demonstrated in the mapping.

All of the atypical supply chain systems investigated and mapped to date demonstrate a flow of goods and services. As such, they could be measured and improved in similar ways to commercial supply chain systems.

There is a plural of responsibility within an atypical supply chain system, where there is a moral and contractual obligation to the recipient and also a contractual and reporting obligation to the funding provider (principal).
The recipient often triggers the demand (need) within an atypical supply system, but the principal (funder) triggers the flow. Two implications of this point occur, these are:

The concept of the end customer needs to be redefined perhaps to "principal"-to avoid potential grey area of reporting and responsibility and also accountability throughout the atypical supply system

In the context of atypical supply systems there is an alignment of the recipient acting as the marketing function of a commercial supply chain system and the end customer (principal) acting as the sales function of a commercial supply chain system [30-31].

\section{Conclusions}

Whereas there has been much investigation around the 
mapping, measuring and improving of commercial supply chain systems, the case is not the same with atypical supply chain systems. There appears to have been some neglect, perhaps because these systems are not considered to be "real" supply chain systems, perhaps because they have been relegated to specialist silos of research and been overlooked by supply chain scholars or perhaps because the plural nature of end customer (principal) and recipient does not fit well with more classical theory. It has been discovered that, by "following the money", it is possible to establish a rich data set and from that data set map an atypical supply chain system.

In the case of aid and development and university research and development atypical supply chain systems, a definite flow of services (i.e. product) has been identified. The identification of flow within these systems suggests that they could be managed using recognised commercial supply chain management tools, and the efficiency improved in the same way improvement has been documented in commercial supply chain systems. It is also reasonable to suggest that if commercial supply chain management tools were applied to atypical supply chains post the mapping phase, then, overall systems clarity and governance might also be improved.

Both of the test cases noted above, demonstrated to be a closed loop system, indicating that the relationship between recipient and end customer (principal) needs to have a close relationship in order to trigger the flow within these atypical supply chain systems. The quality of the relationship between the recipient and end customer (principal) might have a direct effect on what gets funded, when and how. Of itself, this could have significant implications in terms of governance, and legitimacy of the atypical systems that have been triggered (i.e. funded).

Overall, the work to date makes a strong foundation for the argument that atypical supply chain systems should be included into more mainstream supply chain research and not siloed into specialist areas of interest. Within these specialist areas of interest, the basic principles of supply, operations and systems improvement are little, if ever, considered and the focus on efficiency and improvement for the benefit of the customer (in the case of atypical supply chain systems, both the principal and recipient) are often in conflict with typically more softer, shared value type issues that may indeed constrain more impact for less money.

The work to date has highlighted that it is possible to map an atypical supply chain system by "chasing the money". More work is needed in establishing the mapping process and developing it further. Likewise the mapping process needs to be evaluated in other atypical supply chain systems such as those found in government, NGO, not-for-profits and, for example, philanthropy, where accusations of waste, bias and unfortunately corruption often abound. Furthermore, it is suggested that in each case, an exercise of overlaying standard commercial supply chain systems improvement tools should be undertaken to establish a bi-directional efficacy for both the tool in question and the system being evaluated.

\section{REFERENCES}

[1] J.T. Gardner, M.C. Cooper. "Strategic supply chain mapping approaches". Journal of Business Logistics, 24(2): 37-64, 2003.

[2] A. Touboulic, H. Walker. "Theories in sustainable supply chain management: a structured literature review", International Journal of Physical Distribution \& Logistics Management, 45(1/2):16-42, 2015.

[3] 3. Commonwealth of Australia. "Helping the World's Poor through Effective Aid: Australia's Comprehensive Aid Policy Framework to 2015-16", AUSAID, 2012. http://www.budget.gov.au/2012-13/content/ministerial_stat ements/ausaid/html/ausaid-03.htm, Accessed 21 June 2017.

[4] Australian Government. Department of Foreign Affairs and Trade, 2017.

http://dfat.gov.au/aid/who-we-work-with/ngos/Pages/fundi ng-schemes-for-non-government-organisations.aspx, accessed 21 June 2017.

[5] Australian Government. National Innovation and Science Agenda 2015, Commonwealth of Australia, 2015. http://www.innovation.gov.au/system/files/case-study/Nati onal $\% 20$ Innovation $\% 20$ and $\% 20$ Science $\% 20$ Agenda $\% 20$ \%20Report.pdf, accessed 23 February 2016.

[6] W. Easterly. "Are aid agencies improving?" Economic Policy, 22(52): 633-678, 2007.

[7] OECD. "The Paris Declaration on Aid Effectiveness (2005) and the Accra Agenda for Action (2008)". 2005/2008, 2005.

[8] OECD-DAC, 2008 Survey on Monitoring the Paris Declaration, Paris, 2008.

[9] J. Burnley. 21st Century Aid: Recognising success and tackling failure, 137, Oxfam, 2010.

[10] White H. "Evaluating aid impact. Development Aid: A Fresh Look”. Research Paper No. 2007/75, 2007.

[11] P.F. Drucker. "Long-range planning - challenge to management science", Management Science, 5(3): 238-249, 1959 .

[12] W.E. Deming. Out of the Crisis, Massachusetts Institute of Technology, Centre for Advanced Engineering Study, Cambridge, Massachusetts, 1986.

[13] G.J. Plenert. Supply Chain Optimization through Segmentation and Analytics, CRC Press Taylor \& Francis Group, Florida USA, 2014.

[14] M. Christopher. Logistics \& Supply Chain Management. Pearson UK, 2016.

[15] E. Barber. "How to measure the "value" in value chains", 
International Journal of Physical Distribution \& Logistics Management, 38(9): 685-698, 2008.

[16] T. Hines. Supply Chain Strategies: Customer-driven and customer-focused, Butterworth-Heinemann, Oxford, USA, 2006.

[17] P. Bolstorff, R. Rosenbaum. Supply Chain Excellence: A handbook for dramatic improvement using the SCOR model, 2 edn, AMACOM American Management Association, 2007.

[18] S.B. Knouse, P.P. Carson, K.D. Carson, R. Heady. "Improve constantly and forever: The influence of W. Edwards Deming into the twenty-first century", The TQM Journal, 21(5): 449-461, 2009.

[19] M. Habib, C. Jungthirapanich. "Management for the Universities", In INFORMS International Conference on Industrial Engineering and Operations Management, 2010.

[20] E. Goldratt, J. Cox. The Goal, Ashgate Publishing Limited, Surrey, England, 2013.

[21] R. Tricker. ISO9001:2000 for Small Business, Butterworth-Heinemann, Oxford UK, 2003.

[22] International Organisation for Standardization (ISO). https://www.iso.org/iso-9001-quality-management.html, 2015. accessed 21 June 2017.

[23] Australian Research Council, Excellence in Research for Australia. National Report, Australian Government, 2012. http://www.arc.gov.au/era/era_2012/outcomes_2012.htm, accessed 1 February 2014.

[24] USAID. External Program Evaluation Water, Sanitation And Hygiene (WASH) Program In Ethiopia - Final Report,
2008. http://pdf.usaid.gov/pdf docs/Pdacp437.pdf accessed 1 February 2014.

[25] Z. Segetlija, D. Dujak. "Retail Supply Chains and Efficiency of Retail Trade”, Log Forum, 10(3), 2014.

[26] N. Madenas, A. Tiwari, C. Turner, S. Peachey. "An analysis of supply chain issues relating to information flow during the automotive product development". Journal of Manufacturing Technology Management, 26(8): 1158-1176, 2015.

[27] I. Koblen, L. Nizníková. "Selected aspects of the supply chain management in the aerospace industry", INCAS Bulletin, 5(1): 135, 2013.

[28] T. Bohme, S.J. Williams, P. Childerhouse, E. Deakins. "Methodology Challenges Associated with Benchmarking Healthcare Supply Chains", Planning Production \& Control: The Management of Operations, 24(10-11): 1002-1014, 2013.

[29] A.T. Coghlan, H. Preskill, T. Tzavaras Catsambas. "An overview of appreciative inquiry in evaluation", New directions for evaluation, 2003(100): 5-22, 2003.

[30] P. Childerhouse, D. Towill. "Engineering supply chains to match customer requirements". Logistics Information Management, 13(6): 337-346, 2000.

[31] G. Svensson. "The theoretical foundation of supply chain management: A functionalist theory of marketing". International Journal of Physical Distribution \& Logistics Management. 32(9): 734-754, 2002.

[32] J.R. Evans, W.M. Lindsay, W.M. The Management and Control of Quality, South-Western, Cengage Learning, 2011. ISBN 13: 978-0-538-45260-1 